\title{
Exospores and Cysts Formed by Methane-utilizing Bacteria
}

\author{
By R. WHITTENBURY, STEPHANIE L. DAVIES AND J. F. DAVEY \\ Department of General Microbiology, University of Edinburgh, \\ College of Agriculture, West Mains Road, Edinburgh $\mathrm{EH}_{9}{ }_{3} \mathrm{JG}$
}

(Accepted for publication I6 January 1970)

\section{SUMMARY}

Three varieties of resting stage, an exospore and two types of cyst, were formed by methane-utilizing bacteria. Exospores were budded off by two types of organism, both of which underwent a change in morphology prior to spore formation. Exospores possessed some properties in common with endospores: staining properties, some structural features, mode of germination, desiccation and heat resistance, but contained no detectable dipicolinic acid. Some organisms formed desiccation-resistant cysts similar in morphology, staining properties and fine structure to cysts formed by Azotobacter species. Other strains formed non-desiccation-resistant bodies considered to be similar to immature azotobacter-type cysts. A desiccation-resistant cyst formed by one strain differed in structure and appearance from Azotobactertype cysts and was referred to as a 'lipid' cyst.

\section{INTRODUCTION}

Methane-utilizing bacteria are a diverse group of organisms (Whittenbury, Phillips \& Wilkinson, 1970). Many form resting stages, exospores and cysts, which are described in this report.

\section{METHODS}

Organisms. The organisms studied and the media and methods used for growth were described by Whittenbury et al. (1970).

Electron microscopy. The methods were those used by Davies \& Whittenbury (1970) in studies on fine structure of vegetative cells of methane-utilizers. In addition, thin sections were made of organisms embedded in 'Epon' (Luft, 196I) and whole organisms were examined in platinum-shadowed preparations (Bradley, I965).

Resistance tests. Tests were performed on suspensions of vegetative organisms and vegetative organisms + spores or cysts, in nitrate mineral salts medium (NMS). For heat resistance, $0 . \mathrm{I} \mathrm{ml}$. suspension was added to preheated tubes of NMS medium in a constant-temperature water bath. Tubes were removed at various times into crushed ice before serially diluting and plating. To assess desiccation resistance, $0.1 \mathrm{ml}$. suspension was spread on to sterile glass slides, allowed to dry and stored at $30^{\circ}$. Dried preparations were resuspended at intervals and the proportion of vegetative cells to resting stages estimated microscopically before serially diluting and plating or adding to tubes of agar medium.

Assay of components. Dipicolinic acid content of organisms and spores was assayed by the methods of Perry \& Foster (1955) and Janssen, Lund \& Anderson (1958). Assay of poly- $\beta$-hydroxybutyrate was by the method of Law \& Slepecky (I96I). 


\section{RESULTS}

Many strains of methane-utilizing bacteria formed bodies considered to be resting stages in that they possessed survival properties not found in vegetative organisms. Two categories of resting stage were recognized, exospores and cysts.

\section{Exospores}

Exospores were formed by two varieties of methane-utilizer, the 'Methylosinus trichosporium' and 'Methylosinus sporium' strains. Although the exterior morphology of the vegetative organisms and spores of these two varieties differed, the manner of formation and germination of the spores, their fine structure and resistant properties, were similar.

Spore formation and exterior morphology. In the exponential growth phase, bacteria multiplied by constrictive binary fission, no morphological difference being observed between the resultant two organisms. As the culture entered the stationary phase, however, a proportion of the organisms ( 5 to $95 \%$ of the culture depending upon the strains) elongated and tapered either to a pear-shape ('Methylosinus trichosporium', Pl. I, fig. 3) or to a comma-shape ('Methylosinus sporium', Pl. I, fig. 30). This change was irreversible and signalled the onset of spore formation at the tapered end of the organism (opposite to the flagellated pole). The spore, a rounded body (Pl. I, fig. 8, 24), was finally budded off (Pl. I, fig. 7, 24, 29). Organisms which formed the spores failed to form additional spores or to divide, but became granulated and frequently lysed, opening at the tapered end of the organism (Pl. I, fig. 28). Unlysed organisms which had formed spores failed to grow when transferred to fresh medium.

The onset of spore formation was most easily discerned in wet Indian ink preparations of 'Methylosinus trichosporium' strains (Pl. I, fig. I to 9, 25 to 27). The first sign of spore development was the appearance of a second capsule at the tapered end of the organism (Pl. I, fig. 4). This capsule, larger and less well defined than the capsule of the vegetative organism (Pl. I, fig. I), increased in size as the spore developed and remained attached to the budded-off spore (Pl. I, fig. 7,8 ). Negatively stained and platinum-shadowed preparations examined in the electron microscope (Pl. 2, fig. 32 to 34) revealed the fine fibrous nature of the spore capsule which contrasted with the stubby more coarse fibrous nature of the vegetative cell capsule detected in thin sections (Pl. 2, fig. 36). Both capsules remained unstained when treated with conventional capsule stains, including the polysaccharide stain of Hotchkiss (1948), and remained attached after being ultrasonicated for ro min.

Although the spores of 'Methylosinus sporium' did not possess a capsule, the surface of the spores of this variety and of 'Methylosinus trichosporium' strains was similar (Pl. 2, fig. 32, 33, 35).

When freshly formed ( 2 to $3 \mathrm{hr}$ ), spores were not refractile and stained with Gram and other conventional simple stains. On ageing ( $\mathrm{I}$ to 7 days) many spores became refractile and only stained with endospore stains and became acid-fast. Mature spores (refractile) were routinely counted by using the malachite green spore stain (Cruickshank, 1965).

Fine structure. Thin sections of mature spores were difficult to prepare, but some were sufficiently clear in definition to show that both types of spore possessed a similar structure (Pl. 5, fig. 64 to 67 ) which bore some resemblance to that of endospores. An 
outer coat (derived from the wall of the vegetative organism), a laminated inner coat, an area possibly corresponding to the cortex of the endospore, a protoplasmic membrane, and a protoplast were discernible (in that order) in one or more of the sections.

Spore properties. Spores formed by all stains were desiccation-resistant, surviving at least 18 months in a dried state in the absence of methane, and heat-resistant, surviving $85^{\circ}$ for $\mathrm{I} 5 \mathrm{~min}$. Desiccation and heat-resistance correlated with refractility; survival rates of spores increased with an increase in the proportion of refractile to non-refractile spores which, in turn, was a function of increasing age of the spore. Spores were not separated to a significant degree from vegetative organisms by the methods employed

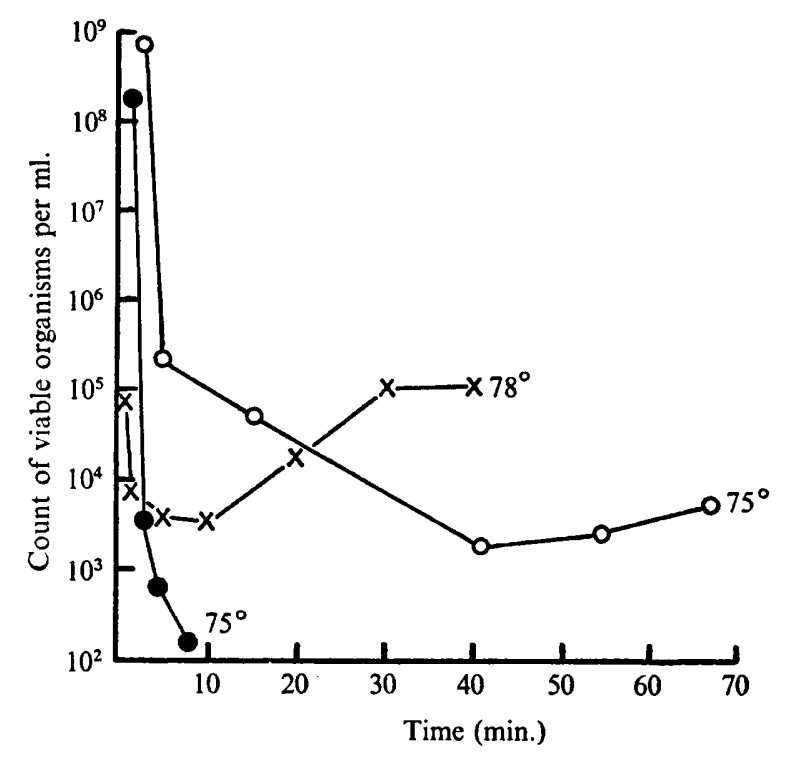

Fig. I. Heat resistance of 'Methylosinus sporium' strain 5 (see Methods). 0 , preparation of vegetative organisms. $\bigcirc \bigcirc$ and $\times \times$, preparations of vegetative organisms and exospores; the sharp decline in viable count in first few minutes is attributed to death of vegetative organisms, and the increase in viable count after a period of heating is attributed to heat stimulation of spore germination.

to separate endospores from vegetative organisms. Consequently survival tests were performed on cultures $(24 \mathrm{hr}$ ), which contained none or a few spores and on cultures (7 or more days) which had spored profusely (Fig. I). This example, a survival curve of spores and vegetative organisms heated at 75 and $78^{\circ}$, also suggested that spore germination was stimulated by heat.

Dipicolinic acid was not detected in spored cultures, either chemically or indirectly by fluorescence under a u.v. microscope. No respiratory activity was detected in spores, in the presence or absence of methane. Mature spores survived ultrasonication for $10 \mathrm{~min}$.

Spore germination. Freshly formed spores (I to $24 \mathrm{hr}$ ) germinated within 2 to 3 days, but old, refractile, spores ( 7 days to 18 months), heat-treated spores and dried spores germinated within 7 to 15 days. Occasionally spores germinated only in patches on uniformly spread plates. Attempts to find a factor which either shortened germination time or promoted uniformity of germination have failed; L-alanine, methanol and 
formate did not alter germination behaviour in the presence of methane and spores did not germinate in the absence of methane.

Germination sequences, followed microscopically on slide cultures, were similar for both varieties of spores and were best demonstrated in Indian ink preparations of a germinating culture of a 'Methylosinus trichosporium' strain (PI. I, fig. 9 to I8) sampled at various times. The capsular coat, only present on 'Methylosinus trichosporium'spores, was frequently shed (Pl. I, fig. I9 to $2 \mathrm{I}$ ) before germination and appeared to play no part in heat and desiccation-resistance properties of the spore. The first visible change in the germinating spore was the loss of refractility (accompanied by loss of acidfastness). Swelling of the spore was not observed: the next visible change was the emergence of a rod which increased in length and either divided or, rarely, formed another spore (Pl. I, fig. 22, 23). The inner spore coat (but not the capsulated outer wall) remained an integral part of the germinating organism (P1. I, fig. I5, I6) for at least two divisions. The germination process, from loss of spore refractility to the first division, lasted for 5 to $7 \mathrm{hr}$.

Spore crop. Spore crops varied from strain to strain (both varieties). On first isolation, all strains spored profusely, but after being subcultured 2 to 3 times, many strains spored sparsely ( $5 \%$ or less of the organisms in a culture sporulated within 7 days). Other strains, however, continued to spore profusely $(90 \%$ of the organisms in a culture sporulating within 7 days). Some of the strains which spored poorly (3 to 5 spores/100 vegetative organisms in 7 days) were stimulated to a higher rate of spore production ( 2 to Io-fold increase) by transferring them to NMS medium from which nitrate had been omitted.

\section{Cysts}

Many methane-utilizers which did not form exospores formed cysts of which there were two distinct varieties, a 'lipid' cyst and an 'Azotobacter-type' cyst. A third variety of resting stage was also recognized, provisionally termed an 'immature' cyst.

'Lipid' cyst. This was formed by only one organism, strain 'Methylocystis parvus', an organism similar in many respects to 'Methylosinus trichosporium' and 'Methylosinus sporium' strains (Whittenbury et al. 1970) and which might have been expected to form an exospore. In the exponential growth phase, the organisms were small rods, free of inclusions and stainable by Gram and other conventional stains. As the organisms entered the stationary phase a proportion of them (varying between less than $5 \%$ to more than $90 \%$ ) formed large lipid inclusions (consisting mainly of poly- $\beta$-hydroxybutyrate) and increased in size ( $\mathrm{Pl} .4$, fig. 54). Old organisms in this phase ( 7 to 14 days) were not stained with Gram or other simple stains, but were stained by the ZiehlNeelson acid-fast stain (Cruickshank, 1965). The fine structure of these lipid organisms differed from that of the vegetative organisms (Pl. 4, fig. 55 to 57). The main differences were an increase in the complexity of the wall of the 'lipid' organism, compared with the vegetative organisms, and the absence from the 'lipid' organism of the complex membrane system seen in the vegetative organism.

A preliminary survey of the resistant properties of the two phases of organism revealed that neither survived $65^{\circ}$ for 30 min., but that the 'lipid' organism survived desiccation, over $80 \%$ remaining viable after $\mathrm{I}$ week when dried on a glass slide. When transferred to fresh medium, the lipid inclusion disappeared and organisms lost their acid-fastness and desiccation resistance. No other changes have yet been detected and nothing is known about the factors influencing cyst formation. 
'Azotobacter-type' cyst. All varieties of 'Methylobacter' ('Methylobacter chroococcum', 'Methylobacter capsulatus', 'Methylobacter bovis', 'Methylobacter vinelandii' and strains not subgrouped) formed multiple, double and single-bodied cysts (Pl. 3, fig. 37 to 49), indistinguishable in microscopic appearance from cysts formed by Azotobacter species. In the exponential phase of growth the organisms were rod or rod/coccal shaped, but as they entered the stationary growth phase many of the organisms (sometimes over $90 \%$ ) rounded up, generally increased in size (Pl. 3, fig. 42, 43) and eventually became refractile. No factor has been found which stimulated cyst production, with the exception that increases in encystment rate have been observed occasionally in cultures growing in the presence of low levels of oxygen. Cyst formation in some strains was prevented by the omission of magnesium ions from the medium. In many cases, profuse encystment was accompanied by the production of a pigment ranging in colour from yellow, to rust to brown, to dark-brown; non-encysted cultures remained creamy white.

Mature, refractile cysts (Pl. 3, fig. 44), stained by the method of Vela \& Wyss (1964), were typical in appearance to stained, mature Azotobacter cysts (a green central body, a clear inner wall space, and a brown outer coat or exine). The structure of the cyst coat (Pl. 4, fig. 58; Pl. 5, fig. 60 to 63) closely resembled that of Azotobacter cysts described by Socolofsky \& Wyss (I96I) and Beaman, Jackson \& Shankel (I968).

Initial experiments on resistance properties revealed that the cysts were not heatresistant but were desiccation-resistant; mature cysts of some strains survived at least I 8 months in a dried state in the absence of methane but others only survived 3 to 4 months. Viability tests of organisms dried on glass slides revealed that 60 to $90 \%$ of the mature cysts survived I week, whilst vegetative organisms did not survive $24 \mathrm{hr}$.

'Immature' cysts. Strains of methane-oxidizing bacteria which did not form desiccation-resistant cysts were classified into 'Methylomonas' (rods) and 'Methylococcus' (cocci) groups. One or more strains in all subgroups (Whittenbury et al. 1970) formed rounded bodies (Pl. 4, fig. 52, 53) which appeared to be immature forms of the 'Azotobacter-type' cyst. Such bodies survived the absence of methane for 5 to 6 weeks in contrast to vegetative organisms which survived only 2 to 3 days and possessed a wall structure (Pl. 4, fig. 59) intermediate between that of a vegetative cell (e.g. Pl. 5, fig. 60) and a mature cyst (e.g. Pl. 4, fig. 58).

\section{DISCUSSION}

Methane-utilizing bacteria use only methane and methanol as energy sources but seem adapted to use only methane in their natural environment as methanol, even in low concentrations (0.0I \% w/v) is toxic to many of them (Whittenbury et al. 1970). The precarious existence the organisms would seem to lead by relying on only one growth substrate, is relieved by the ability of many organisms, probably all, to form resting stages which survive considerable periods of time in the absence of methane. At least three distinct varieties of resting stage are formed, exospores and two types of desiccation-resistant cyst, a 'lipid' cyst and an 'Azotobacter-type' cyst.

The exospores, budded off by two varieties of organism, share some features in common with endospores of Bacillus species. Structurally the exospores are similar to endospores in many respects, with the exception that they lack a well-defined cortex, though this may be a reflexion of inadequate sectioning and staining technique. Heat 
resistance, desiccation resistance, staining properties and mode of spore germination also relate exospores to endospores but the absence of dipicolinic acid in exospores distinguishes them from endospores. Clearly further work is necessary to define more closely the relationship of exospores to endospores.

The 'lipid' cyst, characterized by large lipid inclusions and complex wall structure, bears little resemblance to other bacterial cysts apart from its ability to resist desiccation. 'Azotobacter-type' cysts (although 'Myxococcus-type' would describe them equally well) are similar to those formed by Azotobacter species both in structure and desiccation resistance. A fourth type of resting stage, an 'immature' cyst, may prove to be an incompletely formed 'Azotobacter-type' cyst.

Clearly much remains to be discovered about the nature of these resting stages. Any structural and biochemical properties common to exospores and endospores, cysts formed by these organisms and Azotobacter cysts, should help to identify features specifically concerned with their survival properties.

The authors are grateful to the Department of Zoology, University of Edinburgh, for providing the facilities for electron microscopy. The work was carried out while one of us (S. L. D.) was in receipt of a Science Research Council research fellowship, and was partly financed by a Science Research Council grant to Professor J. F. Wilkinson.

\section{REFERENCES}

Beaman, B. L., Jackson, L. E. \& Shankel, D. M. (I968). Formation of multiple central bodies in giant cysts of Azotobacter vinelandii. Journal of Bacteriology 96, 266.

Bradley, D. E. (1965). Techniques in Electron Microscopy, 2nd ed., p. 96. Edited by D. H. Kay, Oxford: Blackwell Scientific Publications.

Cruickshank, R. (1965). Medical Microbiology, I Ith ed. Edinburgh and London: E. \& S. Livingstone Ltd.

Davies, S. \& WhitTenbuRY, R. (1970). Fine structure of methane and other hydrocarbon-utilizing bacteria. Journal of General Microbiology 6r, 227.

HotchKiss, R. D. (1948). A microchemical reaction resulting in the staining of polysaccharide structures in fixed tissue preparations. Archives of Biochemistry 16, I3I.

JANSSEN, F. W., Lund, A. J. \& ANDERson, L. E. (1958). Colorimetric assay for dipicolinic acid in bacterial spores. Science, New York 127, 26.

LAW, J. A. \& SlePECKY, R. A. (I96I). Assay of poly- $\beta$-hydroxybutyric acid. Journal of Bacteriology 82, 33 .

LUFT, J. H. (1961). Improvements in epoxyresin embedding methods. Journal of Biophysical and Biochemical Cytology 9, 409.

Perry, J. J. \& Foster, J. W. (I955). Studies on the biosynthesis of dipicolinic acid in spores of Bacillus cereus: var. mycoides. Journal of Bacteriology 69, 337.

SOCOlofsKy, M. D. \& WYss, O. (1961). Cysts of Azotobacter. Journal of Bacteriology 81, 946.

VELA, R. G. \& WYSS, O. (1964). Stain for visualization of Azotobacter encystment. Journal of Bacteriology 87,476 .

Whittenbury, R., Phillips, K. C. \& Wilkinson, J. F. (1970). Enrichment, isolation and some properties of methane-utilizing bacteria. Journal of General Microbiology 6r, 205. 


\section{EXPLANATION OF PLATES}

Plate I

Phase-contrast micrographs. Fig. I to 23,25 to 27 are Indian ink preparations, magnification $\times$ 1900, the bar (fig. 25) equals $5 \mu \mathrm{m}$.

Fig. I to 9. Stages in exospore formation by 'Methylosinus trichosporium' strain PG. Capsulated vegetative organism, rod-shaped (fig. I) becomes pear-shaped (fig. 3) and a second capsule develops at the tapered end of the organism (fig. 2 to 3 ). A spore is formed (fig. 4 to 6) and is finally budded off (fig. 6 to 8 ) becomes refractile (fig. 9) and retains the capsule seen developing in fig. 4 .

Fig. Io to 18 . Stages in germination of the exospore of 'Methylosinus trichosporium' strain PG. The spore loses refractility (fig. I0), a rod begins to emerge and the capsule is distorted (fig. I I). Rod increases in size and divides (fig. I 2 to 15 ), the spore coat (but not the capsule) remaining an integral part of the organism after division (fig. I5, I6). The second organism of the pair is a vegetative organism of normal appearance (fig. 17 ) and grows on to divide and form two morphologically similar organisms (fig. I 8).

Fig. I 8 to 2I. Exospores of 'Methylosinus trichosporium' strain PG losing capsule which is probably attached to outer wall of spore (see Pl. 5, fig. 66) and therefore indicates that outer wall is being shed. Fig. 22 to 23. Germinated exospore of 'Methylosinus trichosporium' strain PG forming an exospore. Fig. 24. Preparation (Indian ink omitted) of sporing organism ('Methylosinus trichosporium' strain PG).

Fig. 25 to 27. Rosettes of organisms of 'Methylosinus trichosporium' strain PG in different stages of spore formation.

Fig. 28. Rosette of lysed organisms of 'Methylosinus trichosporium' strain PG. Organisms appear to open at spore bearing pole.

Fig. 29. Exospores, vegetative and sporulating organisms of 'Methylosinus sporium' strain 5.

Fig. 30. Vegetative organisms and organisms in early stage of sporulation, 'Methylosinus sporium' strain 5 .

Fig. 31. Free exospores of 'Methylosinus sporium' strain 5.

Plate 2

Electron micrographs.

Figs. 32, 33. Negatively stained preparations of whole organisms of 'Methylosinus trichosporium' strain PG, showing fine fibres emanating from developing and completed exospore and wrinkled appearance of exospore surface. $\times 16,000$.

Fig. 34. Platinum-shadowed negative of developing exospore of 'Methylosinus trichosporium' strain PG, showing fibres radiating from spore and appearance of spore surface. $\times 16,000$.

Fig. 35. Negatively stained preparation of whole exospore of 'Methylosinus sporium' strain 5. Spore surface is similar in appearance to exospore of 'Methylosinus trichosporium', except that no fine fibres radiate from spore surface. $\times 40,000$.

Fig. 36. Negatively stained thin section of vegetative organism of 'Methylosinus trichosporium' strain PG, showing short fibrous material radiating from wall. This was not seen in preparations of negatively stained whole cells. $\times 60,000$.

\section{Plate 3}

Fig. 37 to 49 . Phase-contrast micrographs of cysts and vegetative organisms of 'Methylobacter' strains, magnification $\times 1900$, bar (fig. 43) equals $5 \mu \mathrm{m}$.

Fig. 37 to 40. Methylobacter capsulatus strain 1521, multiple bodied cysts (arrowed) with part of exine visible and apparently in process of germinating. Cysts in different stages of development (dark round bodies, refractile bodies), empty exines and vegetative organisms (rods) are also present.

Fig. 4I to 43. 'Methylobacter bovis' strain CM, different stages of cyst formation. Mixture of mature cysts (refractile bodies with distinctive outer coats) and cysts apparently released from exine (fig. 4I); vegetative organisms and maturing cysts (fig. 42); and maturing cysts (fig. 43).

Fig. 44 to 45 . 'Methylobacter vinelandii' strain MEXICO, mature refractile cysts and vegetative organisms (fig. 44); maturing cysts (refractile) and vegetative organisms (fig. 45).

Fig. 46 to 49. 'Methylobacter' strain PROVENCE VINE, vegetative organisms and immature cysts (fig. 46); mature cysts (fig. 47); multiple-bodied cyst and vegetative organisms (fig. 48); and large multiplebodied cyst (fig. 49). 


\section{Plate 4}

Fig. 50 to 54. Phase-contrast micrographs, magnification $\times 1900$, bar (fig. 53) equals $5 \mu \mathrm{m}$. Fig. 55 to 59. Negatively stained thin sections.

Fig. 50 to $5 \mathrm{I}$. 'Methylobacter bovis' strain CM, germinating cysts. Exines and emerging organisms (singly and in pairs).

Fig. 52. Methylococcus capsulatus strain ватн. A partially refractile pair of organisms (considered to be immature cysts) amongst vegetative organisms.

Fig. 53. 'Methylococcus minimus' strain TMC. Refractile bodies (considered to be immature cysts) and vegetative organisms.

Fig. 54. 'Methylocystis parvus' strain OBBP. Vegetative organisms (small rods) and lipid cysts (large organisms with inclusions).

Fig. 55. 'Methylocystis parvus' strain овBP; negatively stained thin section of a lipid cyst. $\times 60,000$.

Fig. 56. 'Methylocystis parvus' strain OBBP, negatively stained thin section of lipid cyst showing wall structure. $\times 90,000$.

Fig. 57. 'Methylocystis parvus' strain OBBP, negatively stained thin section of vegetative organism showing wall structure. $\times 90,000$.

Fig. 58. 'Methylobacter bovis' strain CM, negatively stained thin section of mature cyst. $\times 60,000$.

Fig. 59. 'Methylococcus minimus' strain TMC, negatively stained thin section of 'immature' cyst. $\times 60,000$.

\section{Plate 5}

Negatively stained preparations of thin sections.

Fig. 60. 'Methylobacter bovis' strain CM, part of vegetative organism showing wall structure. All 'Methylobacter' strains possessed a similar structure in vegetative state. $\times 90,000$.

Fig. 6I. Methylobacter capsulatus strain I 521 , a cyst. $\times 45,000$.

Fig. 62. 'Methylobacter vinelandii' strain MEXICO, part of a cyst showing laminated coat structure. $\times 90,000$.

Fig. 63. 'Methylobacter bovis' strain CM, part of a mature cyst showing wall structure. $\times 90,000$.

Fig. 64. 'Methylosinus sporium' strain 5, spore showing wall structure. $\times 80,000$.

Fig. 65. 'Methylosinus trichosporium' strain PG spore showing wall structure. $\times 80,000$.

Fig. 66. 'Methylosinus trichosporium' strain PG, part of mature spore. The outer layer (w) derived from vegetative organism in budding process, laminated inner wall $(l)$, area $(c)$ possibly corresponding to cortex of Bacillus endospore, structure $(m)$ possibly corresponding to membrane, and protoplast $(p)$ are evident. The wall layer $(w)$ partially detached in thin section, probably corresponds to the capsulated area detached in whole preparations (PI. 1, fig. 19 to 21 ). $\times 120,000$.

Fig. 67. 'Methylosinus trichosporium' strain PG, part of spore possibly showing an early stage in wall development. $\times$ 120,000. 

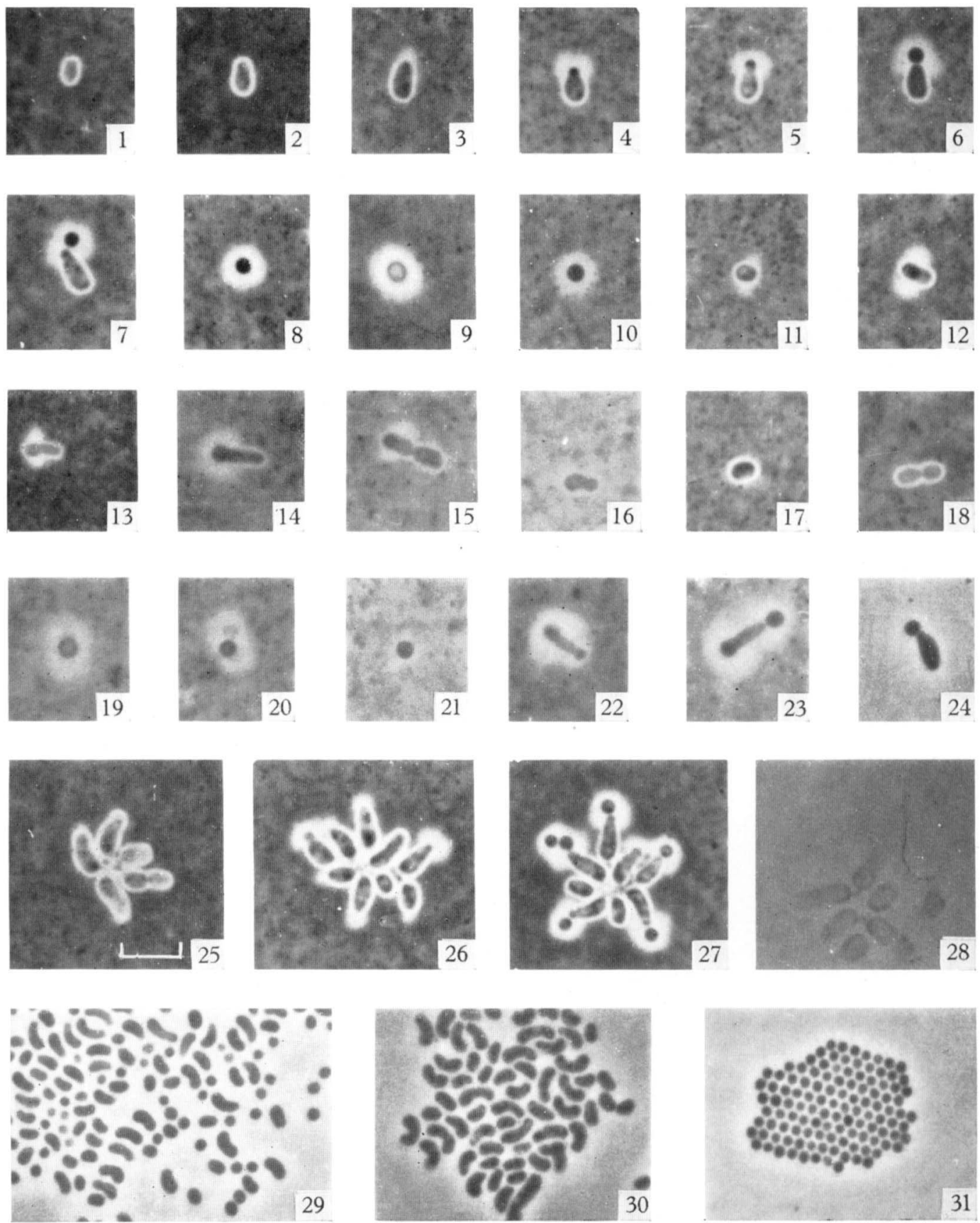
Journal of General Microbiology, Vol. 6I, No. 2

Plate 2
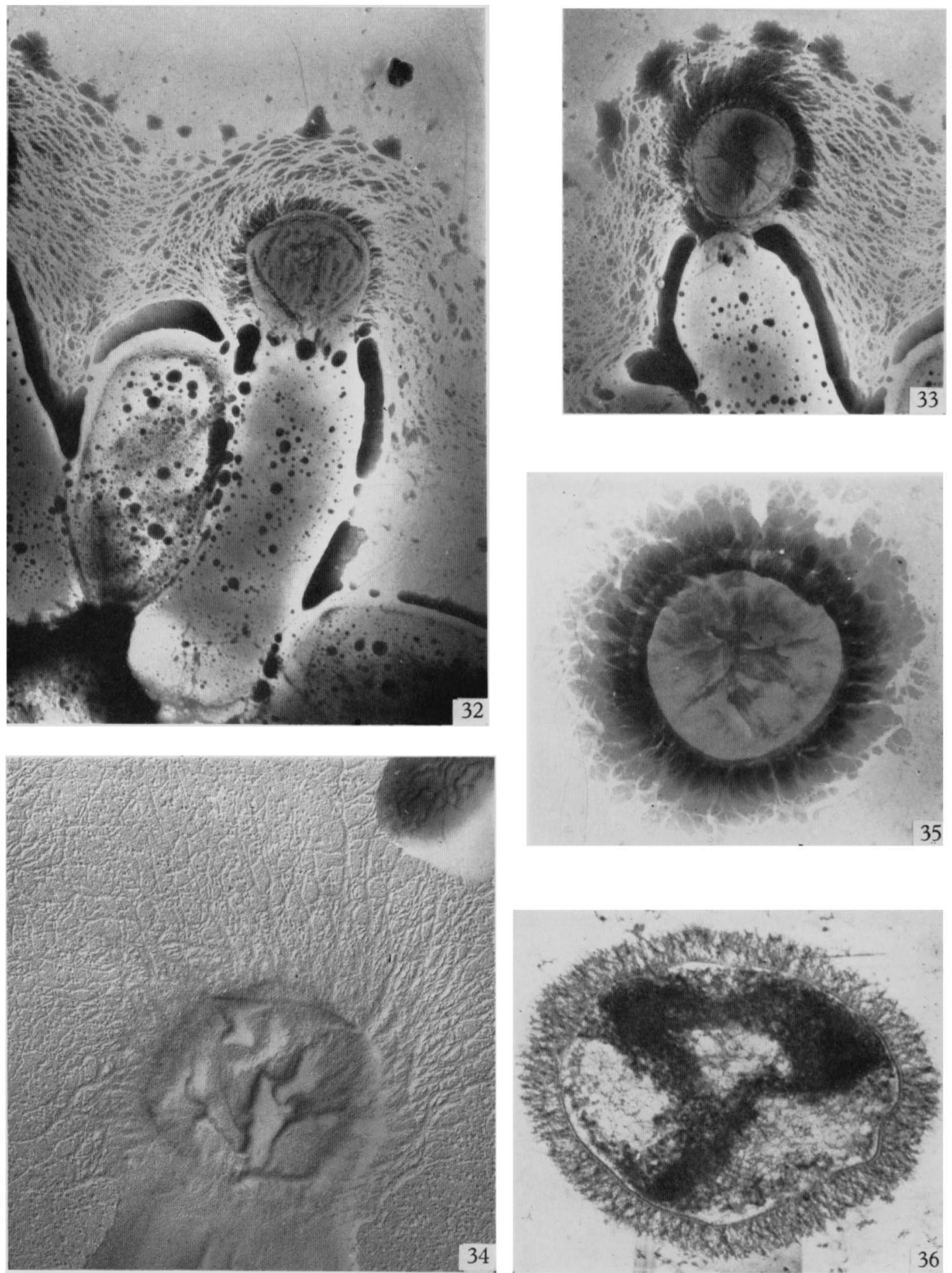

R. WHITTENBURY, S. L. DAVIES AND J. F. DAVEY 

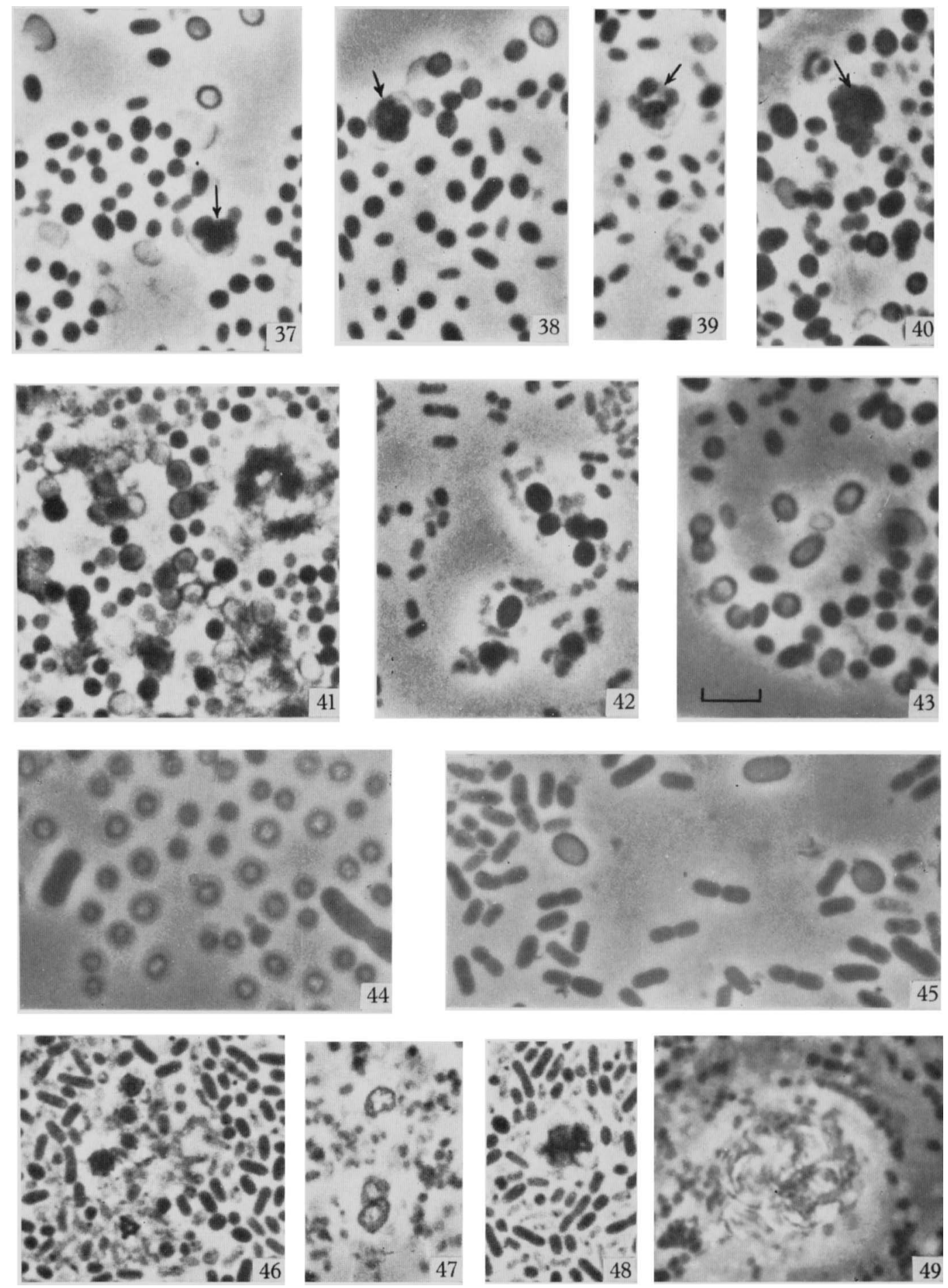

R. WHITTENBURY, S. L. DAVIES AND J. F. DAVEY 

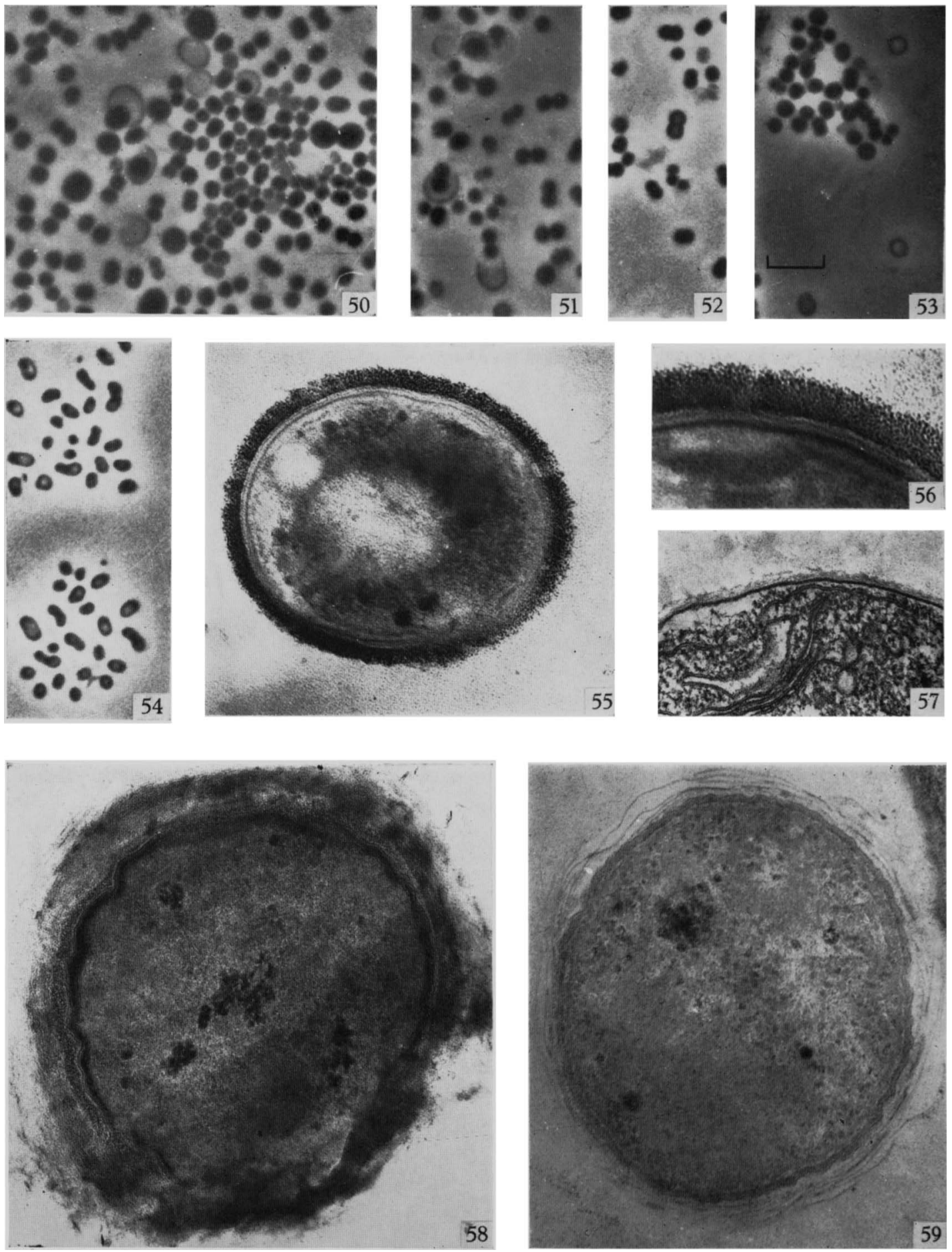

R. WHITTENBURY, S. L. DAVIES AND J. F. DAVEY 

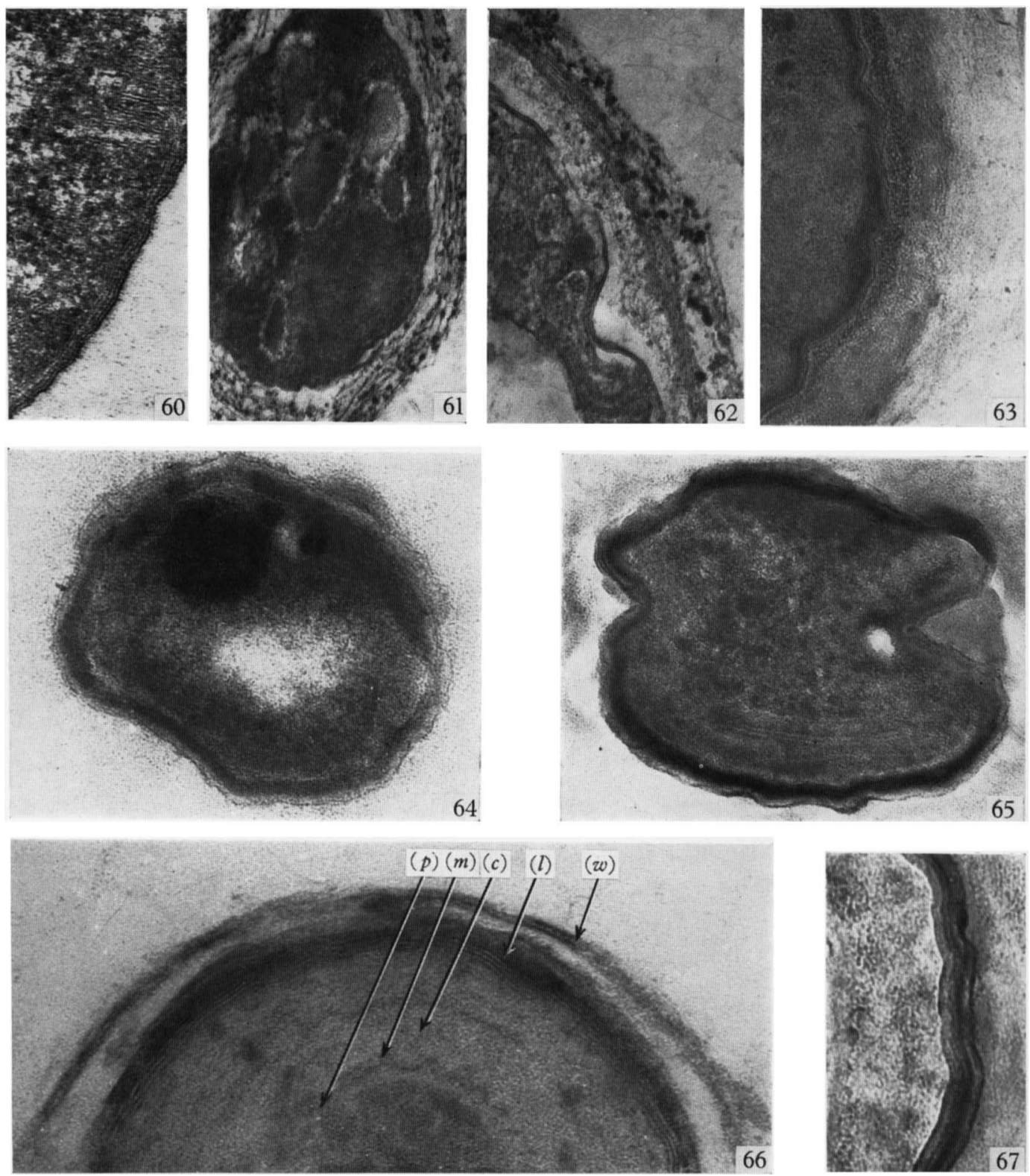

R. WHITTENBURY, S. L. DAVIES AND J. F. DAVEY 